\title{
ELEMENTOS DO TRABALHO VOLUNTÁRIO NA PASTORAL DA CRIANÇA: CARACTERÍSTICAS E MOTIVOS
}

\author{
Laysce R. de Moura \\ Mestranda em Administração - UFRN \\ laysce@gmail.com \\ W. J. de Souza \\ Doutor em Administração - Professor Associado da UFRN \\ wsouza@ufrnet.br
}

\section{RESUMO}

O trabalho voluntário tem crescido significativamente e possui papel importante dentro da sociedade, portanto, é pertinente traçar seus contornos e motivos (adesão, expectativa e permanência). O presente estudo pesquisou a Pastoral da Criança que é organização comunitária que desenvolve há mais de 23 anos um trabalho com o objetivo de desenvolver a criança, combatendo a desnutrição e a mortalidade infantil, além de outras atividades correlacionadas. A pesquisa foi realizada junto à população de voluntários da Pastoral da Criança nos municípios de Limoeiro do Norte e Tianguá localizados no Estado do Ceará, tendo sido obtido um número de 58 respondentes (líderes). Valores altruístas e afetivos estão presentes no trabalho voluntário, caracterizando um voluntariado com elevado grau de abnegação e de dedicação ao bem-estar coletivo.

PALAVRAS-CHAVE: Pastora da Criança; características do trabalho voluntário; motivos do trabalho voluntário. 


\section{ELEMENTOS DO TRABALHO VOLUNTÁRIO NA PASTORAL DA CRIANÇA: CARACTERÍSTICAS E MOTIVOS}

\section{INTRODUÇÃO}

O aparecimento de organizações solidárias e sociais é um fato que tem se intensificado nos últimos tempos devido ao contexto atual, principalmente pelo enfraquecimento do Estado de bem-estar social e pelo fortalecimento do mercado, gerando enormes desigualdades sociais, precarização do trabalho, desemprego estrutural, dentre outros fatores. Essas organizações são caracterizadas por uma forma peculiar de vínculo entre organização e indivíduos que é o trabalho voluntário.

Devido à importância que essas organizações possuem atualmente dentro da sociedade é pertinente traçar contornos do trabalho voluntário e, principalmente, saber quais os motivos que levam o indivíduo à adesão, expectativa e permanência. Literatura no tema (McCurley \& Lynch, 1998; Mostyn, 1983) indica que a filiação ao trabalho voluntário é explicada por um conjunto particular de valores, dentre os quais, o altruísmo, o interesse individual em contribuir e a sociabilidade, além de razões religiosas e sentimentos de culpa, de obrigação ou de responsabilidade.

Com base nesse entendimento, o presente texto traça contornos do trabalho voluntário de pessoas na Pastoral da Criança, tomando como referência experiências de militantes do movimento no estado do Ceará (Limoeiro do Norte e Tianguá).

A Pastoral da Criança é uma organização comunitária com abrangência nacional e leva adiante um trabalho baseado na solidariedade e na partilha do saber. Seu objetivo é o desenvolvimento integral da criança (da concepção aos seis anos de idade) e, por conseqüência, suas famílias e comunidades. Atua no combate à mortalidade infantil, à desnutrição, à violência doméstica e à marginalidade social.

Apesar de ter surgido por iniciativa de líderes da Igreja Católica e estar vinculada à CNBB (Conferência Nacional dos Bispos do Brasil), é um movimento ecumênico e autônomo que agrega o maior volume de trabalho voluntário no Brasil. Seu modelo serve de exemplo para mais quinze nações em três continentes, sob incentivo da Organização das Nações Unidas (ONU).

Instituída há mais de 23 anos, a Pastoral conta com um corpo de voluntários que supera os 270.000, atendendo mais de 2.000.000 de crianças, em 41.542 comunidades de 4.040 municípios (Idéia Social, 2007). Esses números indicam a relevância da organização na promoção do desenvolvimento infantil no país e, por isso, é ambiente privilegiado para estudo do comportamento organizacional em atividade voluntária.

\section{CARACTERÍSTICAS E MOTIVOS DO TRABALHO VOLUNTÁRIO}

O trabalho já teve vários significados para o homem ao longo do tempo e essa variação tem relação com o contexto da época. Segundo Castro (2003) “o trabalho já foi considerado um castigo, um meio de sobrevivência, de criação de valor e utilidade, uma vocação, um instrumento de dignificação do homem”. 
Estudos recentes apontam que a maioria dos homens trabalharia mesmo que não precisassem e as principais razões seriam: se relacionar com outras pessoas, para ter sentimento de vinculação, para ter algo que fazer, para evitar o tédio e para se ter um objetivo na vida (Morin, 2001). Portanto, o trabalho, hoje em dia, é visto de uma forma positiva pelo homem, além de ter um aspecto libertador.

“o homem (a autoconsciência) só se reconhece como ser livre no trabalho (a ação formativa), ao modificar o universo material que o rodeia (o elemento da permanência), tornando efetivos seus próprios desígnios (seu ser para si, a negatividade)” (Enguita, 1989, 11)

Dito de outra forma, o ser humano só se considera livre ao modificar seu contexto e, portanto, o trabalho é o seu meio de vida e o que o torna vivo, parecido consigo mesmo (Codo, 1987).

Cabe chamar a atenção para a diferenciação que se faz entre trabalho (ou ocupação ${ }^{1}$ ) e emprego. Para Fryer e Payne (apud Morin, 2001) o trabalho seria uma atividade útil, determinada por um objetivo definido, além de gerar prazer em sua execução. Já emprego, trata-se do conjunto de atividades remuneradas em um sistema organizado economicamente. Assim, trabalho estaria mais relacionado a atividades compensatórias em si mesmas, enquanto que emprego estaria relacionado à compensação financeira, status e poder.

Dessa forma, o trabalho voluntário pode ser considerado como uma atividade em que o indivíduo desenvolve com o objetivo de se fazer algo útil e prazeroso, além de ser nãocompulsório, não-remunerado e ser movido por motivos tais como altruísmo, interesse próprio, sociabilidade, razões religiosas, afetivas ou aflitivas, resultantes de sentimentos de culpa ou de obrigação para com o outro, ou, ainda, de responsabilidade.

No Brasil, a regulamentação do serviço voluntário se deu mediante a Lei 9.608/98, sancionada pelo então presidente Fernando Henrique Cardoso, em fevereiro de 1998. Apesar da regulamentação a intensificação do incentivo ao trabalho voluntário se deu apenas em 2001, quando a ONU designou como o Ano Internacional do Voluntariado.

A lei define o serviço voluntário como “a atividade não remunerada, prestada por pessoa física a entidade pública de qualquer natureza, ou a instituição privada de fins não lucrativos, que tenha objetivos cívicos, culturais, educacionais, científicos, recreativos ou de assistência social, inclusive mutualidade”.

Não se pode esquecer que no cerne do trabalho voluntário encontra-se o homem que disponibiliza tempo e competências com o intuito de mudar sua realidade que cada dia que passa se torna mais desigual. Para Dhome (2001) voluntário é a pessoa "que doa o seu trabalho, suas potencialidades e talentos em uma função que a desafia e gratifica em prol da realização de uma ação de natureza social”.

O voluntariado vem crescendo no Brasil e no mundo, pois existe a vontade das pessoas de ajudar, mesmo que individualmente, na diminuição das mazelas sociais geradas pela sociedade centrada no mercado. Portanto, é interessante delinear os motivos que fazem 
com que o indivíduo procure executar um trabalho voluntário. Segundo Coleman (apud Cohen, 1964) as pessoas decidem ser voluntários a fim de "conseguir a satisfação da participação em um grupo, o que quer dizer que elas necessitam sentir-se parte de objetivos e significado mais amplos da vida grupal, para obter a satisfação decorrente da dependência, da afeição, da situação social e da realização criadora”.

De uma forma mais objetiva, McCurley \& Lynch (1998) classificaram os motivos do trabalho voluntário em três categorias:

- Altruísta - ajudar aos outros, obrigação de retribuir por algo recebido, dever cívico, convicção religiosa, fazer uma diferença no mundo, crença na causa;

- Interesse próprio - adquirir experiência, desenvolver novas habilidades, constituir amizades, causar boa impressão a alguém, sentir-se importante e útil, exibir capacidade de liderança, experimentar novos estilos de vida e culturas, prazer e alegria;

- Familiar - aproximar a família, servir de exemplo, benefício e retorno próprios, retribuir algo recebido por membro da família.

Já Mostyn (1983) esboçou cinco categorias de organizações voluntárias: altruístas; para ajudar pessoas em situação de aflição; para fornecer ajuda aos menos afortunados; para melhorar a sociedade; por interesse próprio. De comum nessas discussões, é evidente o entendimento de que a decisão para o trabalho voluntário varia em motivos altruístas e o interesse próprio.

Como síntese das categorizações acima, uma Hierarquia do Trabalho Voluntário pode ser delineada em que cada nível de distinção da ação se relaciona com atitudes de sujeitos (Fernandes, 2006). Numa Hierarquia de 5A's seriam contemplados os seguintes níveis:

- Nível I - Altruísta: retrata a percepção subjetiva de auto-sacrifício por parte do voluntário, envolvendo risco, insalubridade e periculosidade, sob a perspectiva da consciência de espécie e de questionamento em torno das condições gerais de vida de seres humanos;

- $\quad$ Nível II - Afetivo: reúne motivos relativos ao sentimento de auxílio a sujeitos e comunidades em situações de exceção, via fornecimento de apoio direto aos menos aptos e prósperos tais como idosos, crianças, desabilitados e pacientes em hospitais, estando o voluntário interessado no resgate da cidadania;

- Nível III - Amigável: contempla motivos vinculados à avaliação subjetiva de contribuição para o bem-estar social, e de desafortunados em particular, sob uma perspectiva amistosa, em que o voluntário se sente compartilhando algo próprio com alguém;

- Nível IV - Ajustado: reúne motivos de uma forma específica de aprimoramento social não centrada em temas cruciais ou aflitivos, mas que, de alguma forma, transmite ao voluntário a sensação de estar, simultaneamente, promovendo a si próprio e a vida do receptor;

- Nível V - Ajuizado: congrega motivos centrados na sensação de privilégios, de status e de proteção, estando o voluntário interessado na construção e projeção da auto-imagem e promoção pessoal junto a indivíduos e coletividades. 
Os motivos variam desde graus mais elevados como o altruísmo até graus mais baixos como o egoísmo. Assim sendo, pode-se afirmar que as ações são movidas tanto pela racionalidade substantiva como pela instrumental.

Serva (1997), baseado na obra de Guerreiro Ramos e Habermas, definiu esses dois conceitos como:
“A ação racional substantiva é orientada para duas dimensões: uma individual, que se refere à autorealização, compreendida como concretização de potencialidades e satisfação; uma grupal, que se refere ao entendimento, nas direções das responsabilidade e satisfação sociais.
A ação racional instrumental é baseada no cálculo, orientada para o alcance de metas técnicas ou de finalidades ligadas a interesses econômicos ou de poder social, através da maximização dos recursos disponíveis.”

Em cima do que foi exposto, uma síntese da tipologia do trabalho voluntário pode ser delineada (Quadro 1) com idéias genéricas cuja manifestação empírica aparece mediada por elementos próximos. Como conjuntos teóricos, tipos, domínios e valores atribuídos são válidos ao exercício de designar, subjetivamente, graus diferenciados de nobreza à ação, sendo essa a fundamentação em que a presente pesquisa se baseia.

QUADRO 1 - SÍNTESE DA TIPOLOGIA DO TRABALHO VOLUNTÁRIO

\begin{tabular}{|l|l|l|l|}
\hline Tipo & Domínio & $\begin{array}{l}\text { Valor } \\
\text { atribuído }\end{array}$ & Questão central \\
\hline Altruísta & $\begin{array}{l}\text { Condição } \\
\text { humana }\end{array}$ & Abnegação & $\begin{array}{l}\text { Como posso contribuir com a } \\
\text { humanidade? }\end{array}$ \\
\hline Afetivo & Coletividades & Dedicação & Como posso promover cidadania? \\
\hline Amigável & Grupos sociais & Amizade & O que tenho a compartilhar? \\
\hline Ajustado & Eu e os outros & Aprendizagem & O que aprendo com isso? \\
\hline Ajuizado & Eu & Ambição & O que ganho com isso? \\
\hline
\end{tabular}

Fonte: elaborado a partir de Mostyn apud Fernandes (2006)

\section{PROCEDIMENTOS METODOLÓGICOS}

Quanto aos meios de investigação, a pesquisa realizada caracteriza-se como estudo de caso e pesquisa de campo. Segundo Yin (2005) “um estudo de caso é uma investigação empírica que investiga um fenômeno contemporâneo dentro de seu contexto da vida real, especialmente quando os limites entre o fenômeno e o contexto não estão claramente definidos”. Trata-se também de uma pesquisa de campo pelo fato da pesquisa empírica ter sido realizada no próprio local do fenômeno através de questionários.

A pesquisa foi realizada junto à população de voluntários da Pastoral da Criança nos municípios de Limoeiro do Norte e Tianguá localizados no Estado do Ceará. A coleta de dados ocorreu em sincronia com o cronograma de reuniões. Participaram da pesquisa aqueles que se encontravam no local e hora previamente agendados, tendo sido obtido um número de 58 respondentes (líderes). Portanto, a amostragem é caracterizada por ter sido não-intencional e não-probabilística. 
Convém chamar atenção para o fato de que os dados, com relação à população de voluntários da Pastoral da Criança, são imprecisos, pois o acompanhamento das filiações e desligamentos é precário. Além disso, existe desinteresse e dificuldade por parte dos voluntários para informarem situações de mudança de endereço, de suspensão temporária da atividade por motivos particulares ou de desistência. Assim, com freqüência, as coordenações não conseguem precisar o número de voluntários atuantes. Essa informação é importante para evidenciar a dinâmica do movimento voluntário e desafios metodológicos que se encontram presentes na investigação desse tipo de atividade.

A pesquisa delineou o perfil sócio-demográfico da população e traçou contornos dos motivos de adesão, expectativas e permanência de voluntários na Pastoral da Criança.

Os dados foram coletados por intermédio de questionário direcionado à caracterização da amostra e à resposta aos objetivos propostos. As questões abertas foram analisadas através de um banco de dados formulado no programa Microsoft Excel, o que tornou possível distribuir as variadas respostas nas dimensões da hierarquia do trabalho voluntário abordada pela pesquisa.

A análise dos resultados foi divida em duas partes. A primeira descreve o perfil sóciodemográfico dos pesquisados. A segunda delineia os contornos dos motivos dos voluntários na Pastoral da Criança.

\section{ANÁLISE DOS RESULTADOS}

A amostra estudada no Ceará - Limoeiro do Norte e Tianguá - possui o seguinte perfil. Em Limoeiro do Norte, no que se refere à idade existe uma distribuição regular nas faixas de idade pesquisada, porém existe uma predominância na faixa etária que vai de 21 a 30 anos (36,6\%). Quanto ao gênero, as mulheres são maioria, representando 96,6\% . O estado civil é de solteiro 63,3\%. No que se refere à situação de moradia, 100\% dos entrevistados residem em casa própria, já em relação à escolaridade 56,6\% concluíram o ensino médio. Quanto ao tempo de atuação na Pastoral da Criança, 60\% dos entrevistados se encontram atuando na Pastoral no período de 6 a 11 meses, mostrando a pouca experiência dos voluntários, afetando na qualidade do trabalho desenvolvido. A média de tempo de atuação na Pastoral gira em torno de 2 anos, pelo fato de existir um percentual significante atuando há mais de 2 anos.

No que se refere à atividade profissional, os dados expressam agricultores 16,7\%. Professores, donas de casa, agente de saúde e estudantes estabelecem com 10\% cada. Autônomos, secretários, com 6,7\% cada. Cabeleireira e auxiliar de serviços gerais 3,3\% cada. No entanto, 23,3\% dos entrevistados não informaram qual a sua atividade profissional.

Com relação à renda própria 46,6\% responderam que possuem renda de até 2 salários mínimos, no entanto 43,3\% não informaram a sua renda. Na renda familiar, 86,6\% dos entrevistados responderam que possuem renda de até 2 salários mínimos e 13,3\% tem renda familiar de 2 a 5 salários mínimos, ficando clara a situação de baixa renda. 
Já em Tianguá o perfil identificado será exposto a seguir. No que se refere à idade $42,8 \%$ se encontram acima dos 41 anos e 35,7 \% entre 31 e 40 anos, indicando a presença majoritária de voluntários adultos. Ainda que exista um percentual significativo entre adolescentes, na faixa etária que vai até 20 anos (17,8\%). Quanto ao gênero, as mulheres são maioria, representando 96,6\%. Quanto ao estado civil 53,5\% são casados, enquanto $42,8 \%$ são solteiros e $3,5 \%$ são viúvos. No que se refere a situação de moradia $78,6 \%$ moram em casa própria. Já em relação à escolaridade, 32,1\% não concluíram o ensino fundamental, $25 \%$ não concluíram o ensino médio, e apenas $21,4 \%$ chegaram a concluir o ensino médio, demonstrando um baixo nível de escolaridade. Quanto ao tempo de atuação na Pastoral da Criança, 46,4\% dos entrevistados estão na Pastoral há mais de 7 anos, o que estabelece uma media de atuação de aproximadamente 8 anos.

No que se refere à atividade profissional, agricultores e donas de casa contabilizam 21,4\% cada. Estudantes, aposentados e professores, estabelecem 10,7\% cada. Agente de saúde e merendeiras com 7,1\% cada. Desempregados, autônomos e não informaram 3,6\% cada.

Com relação à renda própria, 64,2\% informaram ter renda até 2 salários mínimos, enquanto $7,1 \%$ de 2 a 5 salários mínimos e 28,5\% não informaram sua renda. Na renda familiar, $78,5 \%$ tem renda até 2 salários mínimos, 14,2\% de 2 a 5 salários mínimos, enquanto 7,1\% não informaram sua renda. Diante dos dados expostos, mais uma vez, fica clara a situação de baixa renda dos voluntários.

Os contornos dos motivos dos voluntários na Pastoral da Criança serão expostos a seguir e foram analisadas à luz da Hierarquia do Trabalho Voluntário (delineada no item 2 deste texto).

Com o objetivo de traçar os motivos de adesão dos voluntários foi formulada a questão por que você está trabalhando na Pastoral da Criança? Nesse sentido, é importante atentar para o fato de que o voluntário pode alterar a situação preliminar, passando a explicar a permanência por razão diferente daquela que o trouxe ao movimento.

Em Tianguá as respostas para o motivo de filiação situam-se no Nível V da Hierarquia, Ajuizado, com incidência de 48,3\% das respostas. As respostas que melhor representam essa questão são:

"Eu trabalho por que gosto desse trabalho" (líder)

"Só porque eu gosto mesmo" (líder)

Nesse caso, a maior incidência do nível de adesão ocorre devido a elementos de natureza individual. O valor atribuído é de ambição que caracteriza uma perspectiva egoísta. Tal fenômeno não desqualifica o trabalho e o engajamento do voluntário uma vez que, mesmo nesse município, os elementos de permanência ocorrem em nível superior na Hierarquia conforme discussão adiante.

Em Limoeiro do Norte as respostas se concentram no Nível III da Hierarquia, Amigável, com 48,3\% das respostas. As respostas que melhor representam essa questão são:

“Conhecer novas pessoas, passeio, festinhas" (líder).

"A gente conhece muitas pessoas e também a gente aprende muita

coisa” (líder). 
Em Limoeiro do Norte, portanto, a adesão ocorre via motivo de natureza superior na escala quando comparada à Tianguá e está relacionada com valores de amizade.

Com o objetivo de coletar as expectativas dos voluntários em relação ao trabalho realizado por eles foi formulada a pergunta o que você espera obter com o seu trabalho na Pastoral da Criança?

Em Limoeiro do Norte, as respostas se concentraram no Nível I da Hierarquia, Altruísta, com incidência de 51,7\%. As respostas que melhor representam essa questão são:

“[Espero] melhor desenvolvimento das famílias” (líder).

“[Espero] salvar a vida de muitas crianças desnutridas” (líder).

Em Tianguá as respostas convergem igualmente para o Nível Altruísta com 46,4\% com afirmações como:

dignidade” (líder).

“[Espero] um desenvolvimento educacional e social” (líder).

"Espero que meus irmãos tenham uma vida melhor e com

Em síntese, nos espaços pesquisados há elevado grau de expectativas quando se compara com o real potencial de desenvolvimento que pode ser imputado ao papel da Pastoral. Se, por um lado, esse resultado pode promover a permanência do voluntário - em virtude da crença em poder superar mazelas, injustiças e desigualdades que encontram no meio social - por outro lado, pode contribuir - o que é mais factível acreditar - para o desligamento, no instante em que o voluntário passa a se sentir impotente na resolução dos problemas que enfrenta cotidianamente no trabalho.

Com o objetivo de traçar os motivos de permanência foi feita a seguinte indagação: que motivo mantém você na Pastoral da Criança? Em Limoeiro do Norte, novamente, os voluntários permanecem na Pastoral por motivos relacionados à condição humana, com $60 \%$ das respostas convergindo para o nível I da Hierarquia, Altruísta. Nas entrevistas também foi detectada a interferência do nível III da Hierarquia, Amigável, ainda que com menor presença. As respostas que melhor representam essa questão são:

"Primeiro de tudo, o resultado que eu espero é que quando terminar a Pastoral eu ter feito muitas amizades, e também ter ajudado a salvar a vida de muitas crianças desnutridas, e ajudar muitas mães que às vezes coitadas não tem orientação de nada, mas a Pastoral ensina muito, resgatar a vida e a cidadania” (líder).

"A falta de educação vinda da própria formação (das pessoas assistidas), é o que mais me deixa nesse trabalho" (líder).

Em Tianguá os voluntários permanecem no trabalho por questões amigáveis com 45,8\% de incidência nas respostas. As respostas que melhor representam essa questão são:

"Porque eu gosto de conviver com as pessoas" (líder).

“Conhecer novas pessoas e ajudá-las” (líder). 
Há, portanto, permanências explicadas por motivos diversos, com maior grau de altruísmo em Limoeiro do Norte.

\section{CONCLUSÃO}

Os valores que regem o trabalho voluntário são diferentes dos que se dão sob a relação econômico-financeira e são fundados no altruísmo, no desejo de colaborar com o desenvolvimento do outro. Dessa forma, os incentivos salariais, premiações e benefícios materiais não se encontram no centro dos motivos que levam o indivíduo ao trabalho voluntário. A motivação ocorre pela via da solidariedade, pelo prazer e felicidade em promover o bem coletivo. Foi a partir desse entendimento que o presente estudo explorou o universo do trabalho voluntário, visando traçar suas características e motivos (adesão, expectativa e permanência).

A análise dos resultados permite afirmar que os motivos de adesão encontrados não se enquadram em apenas uma dimensão, uma vez que os valores se distribuem entre o Nível III, Amigável (Limoeiro do Norte) e o Nível V, Ajuizado (Tianguá). Resultado interessante, pois atesta uma migração de nível inferior na adesão para nível superior no tocante à permanência (ver Quadro 2). Pode-se observar que parcela considerável de Limoeiro do Norte migra do nível Amigável na adesão para o Nível Altruísta na permanência. Em Tianguá sobem do nível de adesão Ajuizado para o Amigável.

No que se refere ao objetivo que o voluntário busca alcançar com trabalho na Pastoral é notório o interesse por promover o bem-estar da população atendida, por fazer o bem a pessoas humildes e por promover cidadania. Os motivos de permanência encontram-se no Nível I e III da Hierarquia, atestando graus de abnegação e de amizade do voluntário junto ao público que assiste. O interesse próprio - como gostar de crianças - e a Fé Cristã como amor a Deus e missão divina - são pouco anunciados. Especialmente no que se refere ao registro a valores religiosos, o dado é interessante já que se trata de organização vinculada à Igreja Católica, mais especificamente à Confederação Nacional dos Bispos do Brasil (CNBB), sendo factível esperar a noção de caridade e de missão religiosa por parte do voluntariado. Prevalecem, todavia, valores de ordem política, vinculados ao exercício e à promoção da cidadania.

O quadro a seguir sintetiza os dados relacionados aos motivos de adesão, de expectativas e de permanência dos voluntários nos dois espaços pesquisados.

\section{QUADRO 2 - SÍNTESE DE MOTIVOS DE ADESÃO, EXPECTATIVA E PERMANÊNCIA}

\begin{tabular}{|l|l|l|l|}
\hline \multirow{2}{*}{ Espaço investigado } & \multicolumn{3}{|c|}{ Motivos } \\
\cline { 2 - 4 } & Adesão & Expectativa & Permanência \\
\hline Limoeiro & III Amigável - 48\% & I Altruísta - 46\% & I Altruísta - 60\% \\
\hline Tianguá & V Ajuizado - 46\% & I Altruísta - 52\% & III Amigável - 46\% \\
\hline
\end{tabular}

Fonte: própria pesquisa

Percebe-se que os voluntários apresentam motivos diversos com relação à adesão, à expectativa e à permanência, mas os valores de abnegação e amizade são os que 
predominam, caracterizando assim o trabalho voluntário como regido principalmente por valores altruístas que objetivam a promoção do bem estar do próximo, da comunidade e da sociedade.

A pesquisa se defrontou com alguns fatores limitantes. Um deles é o fato dos voluntários apresentarem deficiências na formação, ainda que o perfil tenha indicado um bom nível de escolaridade. Esse fato prejudicou a qualidade das respostas, pois se observou que frequentemente os voluntários não respondiam o que era perguntado.

Outro fator limitante deve ser registrado: a dificuldade na identificação do número de voluntários vinculados às dioceses, áreas e comunidades. Como a Pastoral não tem banco de dados do voluntariado, a coleta sofre, necessariamente, atrasos em virtude do tempo demandado pelas coordenações para informar o número de voluntários que atua em dada comunidade.

Apesar das dificuldades encontradas, o presente estudo levantou dados importantes e alcançou o objetivo inicial de traçar os contornos do trabalho voluntário na Pastoral da Criança.

\section{NOTAS}

${ }^{1}$ Guerreiro Ramos faz uma distinção entre ocupação e emprego. Ocupação está mais relacionada às atividades exercidas dentro das sociedades pré-industriais. Já emprego, surgido com a sociedade de mercado, está relacionado com as atividades exercidas dentro de uma organização formal e serve de critério para definir a significação social do indivíduo.

\section{REFERÊNCIAS}

Castro, Celso A. Pinheiro de. Sociologia Aplicada à Administração. 2.ed. São Paulo: Atlas, 2003.

Codo, Wanderley. O que é alienação. São Paulo: Brasiliense, 1992.

Cohen, Nathan E. O papel do voluntário na sociedade moderna. Lisboa: Fundo de Cultura, 1964.

Dohme, Vânia D’ Angelo. Voluntariado - equipes produtivas: como liderar ou fazer parte de uma delas. São Paulo: Editora Mackenzie, 2001.

Enguita, Mariano F. A face oculta da escola: educação e trabalho no capitalismo. Porto Alegre: Artes Medicas, 1989.

Fernandes, Carla Liliane de Melo. Tipologia do trabalho voluntário e rotatividade de pessoas: o caso da Pastoral da Criança em Natal/RN. Natal: UFRN, CCSA, 2006. [Monografia de Graduação]

Idéia Social. A doutora dos mais pobres entre os pobres. 7. ed. São Paulo: Março, 2007. 
Ioschpe, Evelyn Berg (org.). $3^{\mathbf{0}}$ Setor: desenvolvimento social sustentado. 2.ed. São Paulo: Editora Paz e Terra, 2000.

Minayo, Maria C. de Souza (org.). Pesquisa Social: teoria, método e criatividade. Petrópolis, RJ: Vozes, 1994.

McCurley, S.; Lynch, R. Essencial volunteer management. 2. ed. Londres: The Directory of Social Change, 1998.

Morin, Estelle. Os sentidos do trabalho. Revista RAE, São Paulo, v.41, n.3, p.10, jul/set. 2001.

Mostyn, B. The meaning of volunteer work: a qualitative investigation. In: HATCH, S. (org) Volunteers: patterns, meanings \& motives. Hertz (Reino Unido): The Volunteer Centre, 1983.

Pastoral da Criança. Histórico da pastoral. Disponível em:

<www.pastoraldacrianca.org.br> Acesso em: 06 de julho de 2007.

Portal do Voluntário. Descrição do voluntário segundo a lei $\mathbf{n}^{\mathbf{0}} \mathbf{9 . 6 0 8 / 9 8}$ de fevereiro de 1998. Disponível em: <http://www.portaldovoluntario.org.br> Acesso em: 06 de julho de 2007.

Ramos, A. G. A nova ciência das organizações: uma reconceituação da riqueza das nações. 2. ed. Rio de Janeiro: FGV, 1989.

Rifkin, Jeremy. O Fim dos Empregos: o declínio inevitável dos níveis dos empregos e a redução da força global de trabalho. São Paulo: Makron Books, 1995.

Serva, $M$. A racionalidade substantiva demonstrada na prática administrativa. Revista de administração de empresas. São Paulo, v 37, n.2, p. 18-30, 1997.

Vergara, Sylvia Constant. Projetos e Relatórios de Pesquisa em Administração. São Paulo: Atlas, 1997.

Yin, Robert K. Estudo de caso: planejamento e métodos. 3.ed. Porto Alegre, RS: Bookman, 2005. 